\section{Pneumothorax: A rare or underreported complication following latissimus dorsi muscle flap}

Sir,

Latissimus dorsi (LD) is one of the most commonly used muscles for coverage of moderate-to-large-sized defects post-tumour excision or trauma.

Seroma $(21 \%-79 \%)$ is the most common donor site complication after LD muscle harvest. ${ }^{[1]}$ Other common complications include haematoma, skin margin necrosis and contour deformity. ${ }^{[2]}$ Rarely, brachial plexus injury and lumbar hernia are also reported.

Pneumothorax following LD harvest is a potential and probably an underreported complication. ${ }^{\mid 2,3]}$ We report two patients who developed pneumothorax after raising the flap. Both patients sustained GustiloAnderson type III B lower limb fracture. There were no pre-operative symptoms or signs suggestive of chest trauma in either of them. They underwent debridement, skeletal stabilisation with external fixator and microvascular LD flap cover. LD muscle was raised in a standard manner after infiltrating local anaesthetic solution over the back. After completion of the muscle harvest, intermittent quilting sutures were taken on the back to reduce the dead space and prevent seroma formation. Intra-operative and immediate post-operative periods were uneventful. However, on the second post-operative day, both the patients complained of tightness of the chest and difficulty in breathing. There was decreased air entry on the donor side. X-ray revealed pneumothorax with collapse of ipsilateral lung. Emergency intercostal drain (ICD) was put. Chest physiotherapy with incentive spirometer was started. The pneumothorax resolved and lung 
expanded fully with the treatment. ICD was removed after $48 \mathrm{~h}$.

Pneumothorax is always a possible complication during chest wall and breast surgeries. Infiltration of local anaesthesia with adrenaline requires multiple pricks, and in thin built patients, it may lead to inadvertent injury to the pleural cavity. ${ }^{[2-4]}$ It can also occur while accessing a jugular/subclavian intravenous line during these surgeries. ${ }^{[5]}$ Further, the technique of quilting sutures for reducing dead space can cause this injury. Finally, pneumothorax can also occur during use of electrocautery for dissection of the muscle from posterior chest wall.

In our cases, the most probable cause for pneumothorax was injury while infiltrating local anaesthetic solution. This risk was avoided using blunt tip infusion cannula for infiltrating local anaesthetic solution. Furthermore, quilting sutures should be taken by avoiding the intercostal spaces. Electrocautery should be used carefully when dissecting the muscle off the posterior chest wall.

Awareness of this rare and probably underreported complication can help in avoiding injury to the pleura during flap harvest.

\section{Financial support and sponsorship}

Nil.

\section{Conflicts of interest}

There are no conflicts of interest.

\section{Amish Jayantilal Gohil, Subhash Sahu, Shashank Lamba, Ashish Kumar Gupta}

Department of Plastic and Reconstructive Surgery, Christian Medical College, Vellore, Tamil Nadu, India
Address for correspondence:

Dr. Amish Jayantilal Gohil,

Department of Plastic and Reconstructive Surgery, Christian Medical College, Vellore, Tamilnadu, India. E-mail: amishjg@gmail.com

\section{REFERENCES}

1. Hart AM, Duggal C, Pinell-White X, Losken A. A prospective randomized trial of the efficacy of fibrin glue, triamcinolone acetonide, and quilting sutures in seroma prevention after latissimus dorsi breast reconstruction. Plast Reconstr Surg 2017;139:854e-863e.

2. Gandamihardja TA, Chew BK, Weiler-Mithoff EM. Pneumothorax following extended latissimus dorsi flap breast reconstruction: Rare complication or coincidence? J Plast Reconstr Aesthet Surg 2013;66:1442-4.

3. Osborn JM, Stevenson TR. Pneumothorax as a complication of breast augmentation. Plast Reconstr Surg 2005;116:1122-6.

4. Reekie T, McGill D, Marshall E. Diagnosing intraoperative pneumothorax in patients undergoing autologous breast reconstruction: A useful clinical sign. Case Rep Surg 2014;2014:308485.

5. Cronen MC, Cronen PW, Arino P, Ellis K. Delayed pneumothorax after subclavian vein catheterization and positive pressure ventilation. Br J Anaesth 1991;67:480-2.

This is an open access journal, and articles are distributed under the terms of the Creative Commons Attribution-NonCommercial-ShareAlike 4.0 License, which allows others to remix, tweak, and build upon the work non-commercially, as long as appropriate credit is given and the new creations are licensed under the identical terms.

\begin{tabular}{|l|l|}
\hline \multicolumn{2}{|c|}{ Access this article online } \\
\hline Quick Response Code: & Website: \\
\hline & www.jps.org \\
\cline { 2 - 2 } & DOI: \\
\hline
\end{tabular}

How to cite this article: Gohil AJ, Sahu S, Lamba S, Gupta AK. Pneumothorax: A rare or underreported complication following latissimus dorsi muscle flap. Indian J Plast Surg 2018;51:105-6.

๑ 2018 Indian Journal of Plastic Surgery | Published by Wolters Kluwer - Medknow 